\title{
Application of polyurethane in the production of shoe soles
}

Ivona Rajić ${ }^{1}$, Emi Govorčin Bajsić ${ }^{1}$, Tamara Holjevac Grgurić ${ }^{2^{\star}}$

1 University of Zagreb, Faculty of Chemical Engineering and Technology, Zagreb, Croatia

${ }^{2}$ University of Zagreb, Faculty of Metallurgy, Sisak, Croatia

*tholjev@simet.hr

Original Scientific Paper DOI: $10.34187 /$ ko.69.1.2

\begin{abstract}
Good footwear should be comfortable, long-lasting and fit for purpose, polyurethanes allow designers to meet all of these objectives. Polyurethanes are used in the footwear industry to make insoles and shoe soles. There are two types of PU soles a polyether and polyester based PU sole. Polyether based PU soles have a high resistance against hydrolysis and low oil resistance while polyester based PU soles have a low resistance against hydrolysis and high oil resistance. In this work thermal and mechanical properties of PU elastomers with polyether and polyester polols with different hard segment content were investigated. Differential scanning calorimetry (DSC) indicated partial crystalinity structure of the PU elastomers. PU elastomers based on polyether type polyol show the higher degree of crystalization. Based on DMA results, $\mathrm{T}_{\mathrm{g}}$ values of the PU increases and broadened with increasing hard segment content in the PU elastomers based on polyester polyol, due to the interaction between the urethane groups and the ester carbonyl groups. Mechanical studies indicated that the tensile strength of PU elastomers increased with hard segment.
\end{abstract}

Keywords: shoe soles, polyurethane elastomers, DSC, DMA, tensile properties

\section{Introduction}

Polyurethane has been used in the footwear industry since the 60 s and has become a very popular material for shoe manufacturers, as it allows obtaining quality, comfortable and durable shoes at a low price. The polyurethane used to make the soles of the shoes stands out with its lightness and resistance to abrasion. Polyurethanes represent a very complex but significant group of highly stable polymers, and their application in human activity is very wide due to their specific structure. Polyurethanes can have a different structure from rigid, cross linked to flexible in elastomeric chains. Polyurethane foams and TPU elastomers have a segmented structure, which is composed of long flexible chains (polyols) connected by aromatic hard segments. Polyurethane elastomers are a group of segmented polyurethanes, which are composed of alternating blocks of hard and soft segment. ${ }^{1,2}$ Soft segments are high molecular weight polyether or polyester polyols, which significantly affect the elastic nature of polyurethane (flexibility) as well as properties at low temperatures, due to low glass transition temperature. ${ }^{3,4}$ Polyether-based polyols generally give elastomers with poorer properties compared to polyester-based polyurethanes. In contrast, polyester-based polyol based elastomers show a lower degree of crystallinity. Hard segments are linear reaction products of diisocyanate component and low molecular weight glycol or diamine as chain extenders. In the preparation of polyurethane elastomers can be used: aromatic, aliphatic and cycloaliphatic diisocyanates and various aliphatic and cycloaliphatic low molecular weight glycols and diamines as chain extenders.

Strong polar bonds between the $\mathrm{H}$-atoms from the urethane or $\mathrm{NH}$ group and the carbonyl oxygen from the adjacent urethane group cause the hard domains to act as a crosslinking for the flexible soft segment. The hard segments segregate into hard domains, which may have varying degrees of order. From the present soft and hard segment, a two-phase structure of polyurethane arises. Polyether-based polyurethanes have excellent antibacterial properties and flexural strength at low temperatures compared to polyurethane polyesters. Due to their properties, polyurethanes are increasingly used in the production of polyurethane foams, pillows, synthetic leather and in the manufacture of shoe soles. Shoe manufacturers have improved the materials in order to significantly reduce the impact force compared to traditional materials. Peng and co-workers have shown significantly better impact resistance of polyurethane footwear which is especially significant for designing of running shoes. ${ }^{5}$ As fast running has become very popular, so successive strong shocks can lead to various types of injuries, it is essential that the soles of the footwear used for this purpose are made of deformable material which can limit the force during the heel impact by absorbing energy. ${ }^{5}$ Polyurethane soles for shoes have been on the market for more than half a century and are divided into two categories: PU soles based on polyether which are very resistant to hydrolysis, and PU soles based on polyester with excellent wear resistance. $\mathrm{PU}$ soles are also made by combining these two types of polyols. PUs are synthesized from the reaction between an isocyanate and a polyol molecule. Their hardness is determined by the proportion of hard segments in the polymer matrix, while their density is the result of the development of $\mathrm{CO} 2$ formed by the reaction of isocyanates and water.

\section{Experimental part}

\subsection{Materials}

Four series of PU elastomers based on polyether (PU ET II and PU ET IV) and polyester (PU ES II and PU ES IV) polyol types with aromatic diisocyanate and content of hard segment, ie different ratios of $\mathrm{NCO} / \mathrm{OH}$ groups in the pre-polymer were prepared. The basic components for the preparation of elastomers and their ratio expressed through the ratio of $\mathrm{NCO} / \mathrm{OH}$ groups in the pre-polymer as well as the proportion of hard segment are shown in Table 1.

Table 1. PU elastomers and their composition

\begin{tabular}{|c|c|c|c|c|c|}
\hline $\begin{array}{c}\mathrm{PU} \\
\text { elastomer }\end{array}$ & $\begin{array}{c}\text { Polyol } \\
\text { (producer) } \\
\text { [commercial } \\
\text { name] }\end{array}$ & $\begin{array}{c}\text { Diisocyanate } \\
\text { (producer) } \\
\text { [commercial } \\
\text { name] }\end{array}$ & $\begin{array}{c}\text { Moleculat } \\
\text { weight } \\
\text { polyol }\end{array}$ & $\begin{array}{l}\text { Wight ration } \\
\text { of hard } \\
\text { segment in } \\
\text { prepolymer }\end{array}$ & $\begin{array}{c}\text { Ratio of } \\
\mathrm{NCO} / \mathrm{OH} \\
\text { in prepolymer }\end{array}$ \\
\hline $\begin{array}{l}\text { PU ET II } \\
\text { PU ET IV }\end{array}$ & $\begin{array}{l}\text { PTMO } \\
\text { (Du Pont } \\
\text { Comp.) } \\
\text { [Terethane } \\
1000]\end{array}$ & $\begin{array}{c}\text { MDI } \\
\text { (Miles) } \\
\text { [Unilink } \\
4200]\end{array}$ & 1000 & $\begin{array}{l}35 \\
52\end{array}$ & $\begin{array}{l}2 / 1 \\
4 / 1\end{array}$ \\
\hline $\begin{array}{l}\text { PU ES II } \\
\text { PU ES IV }\end{array}$ & $\begin{array}{l}\text { PCL } \\
\text { (Union } \\
\text { Carbide } \\
\text { Corp.) } \\
\text { [Tone 0230] }\end{array}$ & $\begin{array}{c}\text { MDI } \\
\text { (Miles) } \\
\text { [Unilink } \\
4200]\end{array}$ & 1250 & $\begin{array}{l}34 \\
51\end{array}$ & $\begin{array}{l}2 / 1 \\
4 / 1\end{array}$ \\
\hline
\end{tabular}

$\mathrm{OCN}-\mathrm{O}-\mathrm{CH}_{2}-\mathrm{O}-\mathrm{NCO}$

Difenilmetan diizocijanat (MDI)

4,4 '- diphenyl methane diisocyanate

\section{$\mathrm{H}+\mathrm{O}-\mathrm{R}-\mathrm{O}-\stackrel{\mathrm{II}}{\mathrm{C}}-\left(\mathrm{CH}_{2}\right)_{+} \stackrel{\mathrm{I}}{\mathrm{C}}-\mathrm{O}-\mathrm{R}-\mathrm{O}+{ }_{11} \mathrm{H}$}

Poliester poliol sa $\mathrm{R} \equiv \mathrm{CH}_{2} \mathrm{CH}_{2}-\mathrm{O}-\mathrm{CH}_{2} \mathrm{CH}_{2}$ $\mathrm{PCL}$ - poly (- caprolactone) glycol

$$
\begin{aligned}
& \stackrel{\mathrm{CH}_{3}}{\stackrel{\mathrm{CH}_{3}}{\mathrm{I}}} \stackrel{\stackrel{\mathrm{CH}_{3}}{\mathrm{HO}}-\mathrm{CH}_{2}-\mathrm{O}+\mathrm{CH}_{2}-\stackrel{\mathrm{C}}{\mathrm{C}}-\mathrm{O}-{ }_{\mathrm{n}} \mathrm{CH}_{2}-\stackrel{\mathrm{C}}{\mathrm{C}}-\mathrm{OH}}{ } \\
& \text { Polieter poliol }
\end{aligned}
$$$$
\mathrm{HO}-\left(\mathrm{CH}_{2}\right)_{4}-\mathrm{OH}
$$$$
1,4 \text { Butandiol }
$$

PTMO - poly (tetramethylene oxide) glycol

\subsection{Preparation of $P U$ elastomers}

Polyurethane, PU, elastomers were prepared by a pre-polymer process, which takes place in two stages (Figure 1). The first stage refers to the preparation of pre-polymers by polymerization in mass of diisocyanates with polyol. An $\mathrm{NCO} / \mathrm{OH}$ ratio of $2 / 1$ and $4 / 1$ was used. The diisocyanate was dissolved in the reactor at a temperature of $\approx 80^{\circ} \mathrm{C}$ under nitrogen with 
intensely stirring. The diisocyanate was then cooled to $60^{\circ} \mathrm{C}$ and polyol was added with continuous stirring, without a catalyst. The end of the reaction was determined when the difference of the experimental $\mathrm{NCO}$ value in relation to the calculated $\mathrm{NCO}$ value was $\approx 1 \%$. The concentration of $\mathrm{NCO}$ in the isocyanate and pre-polymer was measured by the titration method with di-(n-butyl) amine, ASTM D 2572-80. In the second step, PU elastomers were synthesized by the reaction of pre-polymers and chain extenders, with an $\mathrm{NCO} / \mathrm{OH}$ ratio of 1.05 . For this purpose, the pre-polymer was heated to $90{ }^{\circ} \mathrm{C}$ and 1,4-butanediol chain extender was added with intensively stirring. The reaction mixture is then poured into a heated mold and pressed at $100{ }^{\circ} \mathrm{C}$ for $30 \mathrm{~min}$. After removal from the mold, the elastomers were kept at a temperature of $105^{\circ} \mathrm{C}$ for 24 hours, in order to complete the reaction and crosslinking

$$
\begin{aligned}
& \mathrm{HO}-\left(\mathrm{CH}_{2}\right)_{5}-\mathrm{C}-\ldots+\stackrel{\mathrm{O}}{\mathrm{C}}-\left(\mathrm{CH}_{2}\right)_{5}-\mathrm{O}+_{\mathrm{n}} \mathrm{H}+\mathrm{OCN}-\mathrm{R}_{1}-\mathrm{NCO} \\
& \text { Poliesterskj poliol Diizocijanat }
\end{aligned}
$$

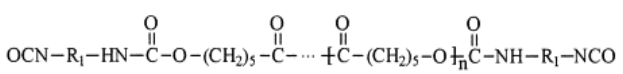

$$
\begin{aligned}
& \begin{array}{l}
+\mathrm{HO}-\mathrm{R}_{2}-\mathrm{OH} \\
\text { Niskomolekulni diol }
\end{array}
\end{aligned}
$$

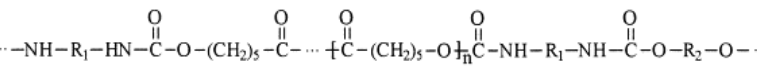

$$
\begin{aligned}
& \text { PUES }
\end{aligned}
$$

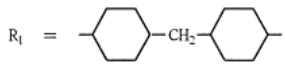

Figure 1. Preparation of PU elastomers with pret-polymer process

\subsection{Characterization}

\subsubsection{Dynamic-mechanical analysis (DMA)}

Dynamic mechanical analyzer DMA 983, TA instruments, was used to measure the primary viscoelastic functions, the storage modulus $E^{\prime}$ and the loss modulus $\mathrm{E}$ ". The measurements were performed at a constant frequency of $1 \mathrm{~Hz}$ with an amplitude of $0.2 \mathrm{~mm}$. The heating rate was $3^{\circ} \mathrm{C}$ $\mathrm{min}$, and the temperature range from $-100{ }^{\circ} \mathrm{C}$ to $200{ }^{\circ} \mathrm{C}$. Sample dimensions were $20.00 \times 13.00 \times 1.00 \mathrm{~mm}$. Liquid nitrogen was used for cooling to low temperatures.

\subsubsection{Differential Scanning Calorimetry (DSC)}

DSC measurements were performed on a Mettler Toledo DSC $822 \mathrm{e}$ instrument. The heating rate was $10^{\circ} \mathrm{C} / \mathrm{min}$. Samples $(10 \mathrm{mg})$ were heated from $25{ }^{\circ} \mathrm{C}$ to $200{ }^{\circ} \mathrm{C}$ with a heating rate of $10^{\circ} \mathrm{C} / \mathrm{min}$ and kept at that temperature for $5 \mathrm{~min}$. in order to "forget" the thermal history of sample preparation. The samples were then cooled to $-100{ }^{\circ} \mathrm{C}$ at a rate of $10{ }^{\circ} \mathrm{C} /$ min, followed by a heating cycle from $-100^{\circ} \mathrm{C}$ to $200^{\circ} \mathrm{C}$. Phase transition values were obtained from these two cycles. The sample weight was $16 \mathrm{mg}$. Cooling to low temperatures was performed with liquid nitrogen.

\subsubsection{Mechanical properties}

The mechanical properties were performed on a universal device for mechanical tests Zwick 1005. The tensile test was performed in accordance with the standard method DIN 53 455. The basic parameters defining the tested system were used: tensile test, temperature $23^{\circ} \mathrm{C}$, relative humidity of $70 \%$, elongation rate of $25 \mathrm{~mm} / \mathrm{min}$, tube dimensions of $90.00 \mathrm{~mm} \times 13.0$ $\mathrm{mm} \times 1.0 \mathrm{~mm}$. Five measurements were performed for each sample.

\section{Results and Discussion \\ 3.1. Results of DSC analysis}

Characteristic thermal transitions in polyurethane (PU) elastomers are: glass transition temperature of soft segment $\left(T_{g}\right)$, melting temperature $\left(T_{m}\right)$ of low and highly ordered hard segment domains and crystallization temperature $\left(T_{c}\right)$ related to the crystal structure of hard segment. The phase transitions in the PU elastomers were determined from the DSC heating curves (Figure 2a) and the DSC cooling curves (Figure 2b), and obtained values are shown in Table 2.

Endothermic and exothermic transitions on the DSC curves indicate a partial crystalline structure of PU elastomers. 6 The glass transition of PU ES IV increases with increasing of hard segment's content $\left(\Delta \mathrm{Tg}=10^{\circ} \mathrm{C}\right)$ relative to PU ES II, as a consequence of reduced soft segment mobility. In
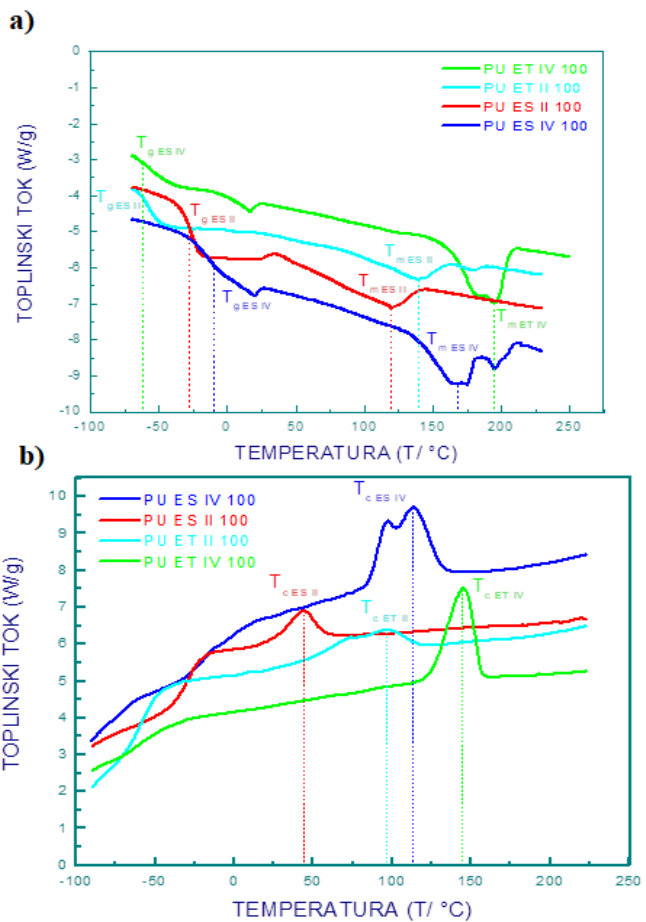

Figure 2. DSC curves: $a$ ) heating and $b$ ) coolong with glass transition, melting and crystalization peak for PU elastomers; PU ET II, PU ET IV, PU ES II i PU ES IV

the polyester PU elastomer there is better miscibility of soft and hard segments, due to stronger interactions of the ester and urethane groups. In the case of PU elastomers with a polyether type of polyol, there is a greater separation of the ether and urethane groups, which is increased by the addition of the hard segment, so $\mathrm{Tg}$ for PU elastomers of the ether type of polyol is obtained at the same temperature of $-56.0^{\circ} \mathrm{C}$ as in ET II.

Endothermic transitions represent the melting point $(\mathrm{Tm})$ of the hard segment. By increasing of hard segment content, increases $T_{m}$ in polyether and polyester PU elastomers. PU elastomers with ether polyol show higher $\mathrm{T}_{\mathrm{m}}$ compared to $\mathrm{PU}$ elastomers with ester type polyol, due to their higher crystallinity. ${ }^{7}$ The obtained fusion enthalpy values $\left(\Delta \mathrm{H}_{\mathrm{m}}\right)$ increase with increasing hard segment content, more significantly for ether type PU elastomers. Based on the values $\left(\Delta \mathrm{H}_{m}\right)$ obtained by DSC measurement, the degree of crystallinity of the PU elastomer $\left(\chi_{c}\right)$ was calculated. For all PU systems, the degree of crystallinity $\chi c$ was calculated using expression (1):

$$
\chi_{c}=\frac{\Delta \mathrm{H}_{m}}{\Delta \mathrm{H}_{m}{ }^{o}} \cdot 100 \%
$$

where $\Delta \mathrm{H}_{\mathrm{m}}(\mathrm{J} / \mathrm{g})$ is value obtained by DSC measurement, while $\Delta \mathrm{H}_{\mathrm{m}}{ }^{0}(\mathrm{~J} / \mathrm{g})$ corresponds to $100 \%$ crystalline PU and it is $24,393 \mathrm{~J} / \mathrm{g} .{ }^{8}{ }^{8}$ The calculated values of the degree of crystallinity increase with increasing content of hard segment and indicate a higher degree of crystallinity of PU elastomers with polyether polyol. The measured values of $\Delta \mathrm{H}_{\mathrm{m}}$ as well as the degree of crystallinity are shown in Table 2 .

Table 2. DSC values of transition temperatures, fusion enthalpy and degree of crystallinity of PU elastomers

\begin{tabular}{|l|c|c|c|c|c|}
\hline PU elastomer & $\mathrm{T}_{g /{ }^{\circ} \mathrm{C}}$ & $\mathrm{T}_{m} /{ }^{\circ} \mathrm{C}$ & $\mathrm{T}_{c} /{ }^{\circ} \mathrm{C}$ & $\Delta \mathrm{H}_{m} / \mathbf{J g}^{-1}$ & $\chi_{c / \%}$ \\
\hline PU ET II & -56.4 & 138.2 & 95.6 & 8.57 & 35.13 \\
PU ET IV & -56.7 & 194.5 & 145.3 & 17.49 & 71.70 \\
\hline PU ES II & -27.0 & 119.6 & 44.02 & 5.24 & 21.48 \\
PU ES IV & -16.4 & 164.4 & 113.9 & 10.26 & 42.06 \\
\hline
\end{tabular}

$\mathbf{T}_{\mathrm{g}}$-glass transition of soft segment, $\mathbf{T}_{\mathrm{m}}$-melting temperature of hard segment, $\mathbf{T}_{c}$ - crystallinity of hard segment, $\Delta \mathrm{H}_{\mathrm{m}}{ }^{0}$ - fusion enthalpy, $\Delta \mathrm{H}_{\mathrm{m}}{ }^{0}$ fuion enthalpy for $100 \%$ crystalline PU $(24,393 \mathrm{~J} / \mathrm{g})^{8} \mathrm{XC}$ - degree of crystallinity

\subsection{Results of DMA analysis}

The viscoelastic properties of PU samples are determined by dynamic 
mechanical analysis (DMA). The obtained relaxation transitions provide insight into the structure of the investigated material. Further, from DMA measurements it is also possible to follow the polymer-polymer interaction and miscibility of the components in polymer mixture. The results show the effect of the hard segment and type of polyol on the properties of PU elastomers. Figure 3 a) shows the curves of loss modulus ( $E$ "), and Figure $3 \mathrm{~b}$ ) the curves of storage modulus ( $E$ ') as a function of temperature for PU elastomers, based on ether (PU ET) and ester (PU ES) type polyols. The obtained values are presented in Table 3 . Tg of the soft elastomeric phase in PU occurs at temperatures below room temperature and its value depends on the content of the hard segment and the type of polyol.

a)

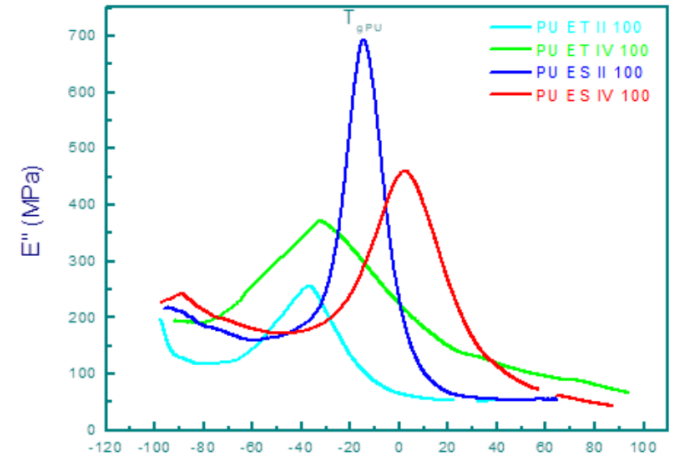

b)

TEMPERATURA $\left(\mathrm{T} /{ }^{\circ} \mathrm{C}\right)$

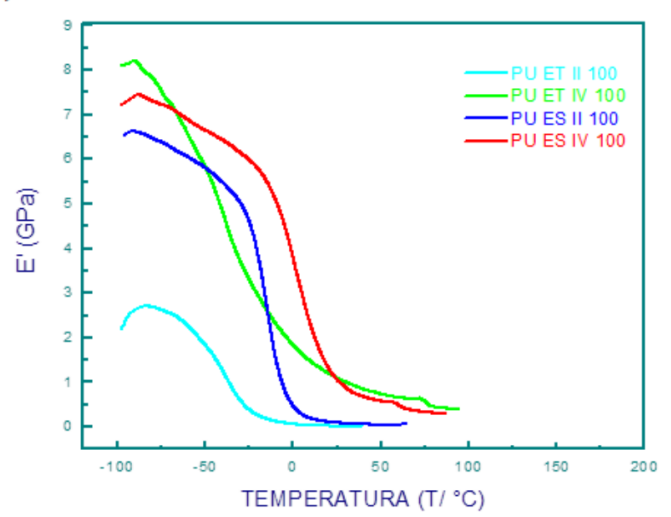

Figure 3. DMA curves of a) loss modulus ( $\left.E^{\prime \prime}\right)$ and $b$ ) storage modulus ( $\left.E^{\prime}\right)$ vs. T for PU elastomers; PU ET II, PU ET IV, PU ES II i PU ES IV

Weak interactions between the ether and urethane groups lead to the separation of the soft and hard segments, which is more pronounced with the higher content of the hard segment, what is also confirmed by DSC analysis. Ester groups in PU polyester have better interactions with urethane groups, leading to a shifting of $\mathrm{Tg}$ to higher temperatures as well as wider relaxation maximum in PU elastomers with a higher content of hard segment (PU ES IV). Increasing of hard segment content in PU elastomers based on ether and ester type of polyol, leads to a shifting of the storage modulus $\mathrm{E}^{\prime}$ to higher temperatures, what indicates an increasing of material's stiffness.

Table 3. Storage and loss modulus E"/T i E'/T for PU elastomers

\begin{tabular}{|l|c|c|}
\hline PU elastomer & $\begin{array}{c}\mathrm{T}_{g P U} \\
\left({ }^{\circ} \mathrm{C}\right)\end{array}$ & $\begin{array}{c}\mathrm{E}_{25}{ }^{\circ} \mathrm{C} \\
(\mathrm{GPa})\end{array}$ \\
\hline PU ET II & -37.1 & 0.02 \\
PU ET IV & -37.7 & 1.094 \\
\hline PU ES II & -14.6 & 0.09 \\
PU ES IV & 2.2 & 1.050 \\
\hline
\end{tabular}

$\mathrm{T}_{\mathrm{g}} \mathrm{PU}$ - glass trasnition of soft segment of PU elastomers, $\mathrm{E}^{\prime} 25^{\circ} \mathrm{C}$ - storage modulus at $25^{\circ} \mathrm{C}$

\subsection{The effect of hard segment content and polyol type on the mechanical properties}

Insight into component adhesion in polymer mixture can be obtained by measurements of mechanical properties, ie tensile strength $(\sigma)$ and elongation $(\varepsilon)$. Figure 4 shows the stress strain curves for PU elastomers, and measured values are presented in Table 4.

Woods confirmed that mechanical properties of $\mathrm{PU}$ are influenced by the structures and reactivity of isocyanates. ${ }^{9}$ Aromatic (MDI) isocyanate polyurethane elastomers have good tensile properties due to their high reactivity and ordered $\mathrm{H}$-bond structure between the urethane groups in the hard segment. From the Figure 4 it can be seen that PU shows low tensile strength and high elongation. Increasing of the hard segment content

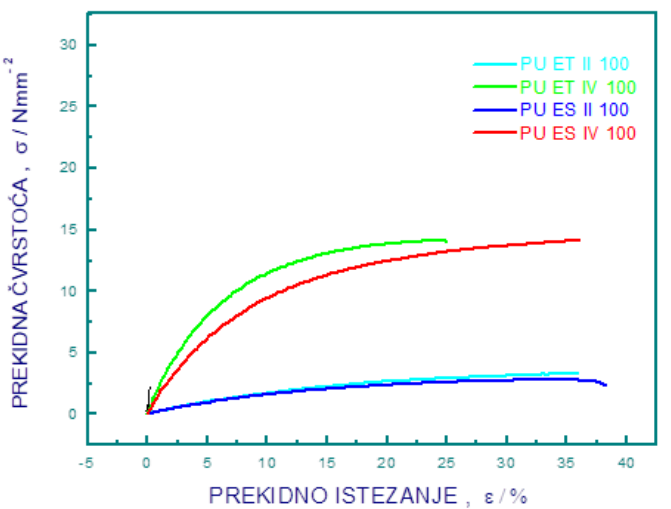

Figure 4. Stress-strain curves for PU elastomers based on ether (PU ET) and ester (PU ES) type polyols

results in an increasing of tensile strength and decreasing of elongation of polyether (PU ET) and polyester type (PU ES) PU elastomers. PU elastomers with ether polyol have slightly higher values of tensile strength and lower values of tensile elongation compared to ester PU elastomers, due to the ordered crystal structure of PTMO, which is formed during the elongation of macromolecule chains. ${ }^{10}$

\begin{tabular}{|l|c|c|}
\hline PU elastomers & $(\mathrm{MPa})$ & $\sigma_{R}$ \\
\hline PU ET II & 3.5 & $\varepsilon_{R}(\boldsymbol{\%})$ \\
PU ET IV & 14.1 & 36.0 \\
& & 25.0 \\
\hline PU ES II & 2.3 & 38.0 \\
PU ES IV & 13.6 & 36.0 \\
\hline
\end{tabular}

$$
\sigma_{p} \text { - tensile sterngth, } \varepsilon_{p} \text { - elongation }
$$

\section{Conclusion}

The results of DSC measurement indicate a partial crystalline structure of PU elastomers. Due to the stronger interactions of the ester and urethane groups in the PU elastomer based on polyester, better miscibility of soft and hard segments was obtained in those samples. The degree of crystallinity increases with increasing content of hard segment in both types of polyols, but a higher degree of crystallinity was obtained for PU elastomers with polyether polyol. The glass transition in PU elastomers based on the ester type of polyol was shifted to higher temperatures and relaxation maximum on the curve $E$ " / $T$ became wider by increasing the hard segment content in elastomers (PU ES IV elastomer). Storage modulus values (E / T) increase with the increasing of the hard segment content in the both PU elastomer, ether and ester type of polyol, which indicates an increasing stiffness of the material. The tensile strength also increases, but elongation decreases in the polyether and polyester type PU elastomers. PU elastomers with ether polyol have slightly higher values of tensile strength and lower values of tensile elongation compared to ester PU elastomers.

\section{Literature}

[1] S. L. Cooper, A. V. Tobolsky, J Appl Polym Sci 10 (1966) 1837-1844

[2] C.S.Schollenberger, H. Scott, G.R. Moore, RubberWorld 137 (1958) 549-555

[3] S. Sarkar, B. Adhikari, Polym. Degrad. Stabil.73 (2001) 169-175

[4] J. Ferguson, Z. Petrovic, Eur. Polym. 12 (1976) 177-181

[5] Piaolin Penga, Shaolan Dinga, Zhikang Wang, Yifan Zhang, Jiahao Pan (2020), Acute effect of engineered thermoplastic polyurethane elastomer knockoff running footwear on foot loading and comfort during heel-to-toe running, Gait \& Posture, 111

[6] J. Blachwell, C.D. Lee, Advances in Urethane Science and Technology, K.C Frisch and D.Klempner, Eds., Tehnomic, Stanford, Conn 1994

[7] G.J. Ralf, C. Heijhants, T. G. van Tienen, P. Buma, A.J. Pennings, A.J Schouten, Biomaterials, 26 (2005) 4219-4228

[8] C.P. Papandopoulow, N.K. Polymer, 39 (1998) 7015

[9] G. Woods, The ICI Polyurethane Book (second ed.), Wiley, (1990)

[10] S. Subramani, I. Cheong and J.H. Kim, Progres in Organic Coatings, 51, 4 (2004) 328-338 